\title{
Neuromodulatory Inputs Maintain Expression of a Lobster Motor Pattern-Generating Network in a Modulation-Dependent State: Evidence from Long-Term Decentralization In Vitro
}

\author{
Muriel Thoby-Brisson and John Simmers \\ Laboratoire de Neurobiologie des Réseaux, Université de Bordeaux I and Centre National de la Recherche Scientifique, \\ 33120 Arcachon, France
}

\begin{abstract}
Neuromodulatory inputs play a critical role in governing the expression of rhythmic motor output by the pyloric network in the crustacean stomatogastric ganglion (STG). When these inputs are removed by cutting the primarily afferent stomatogastric nerve (stn) to the STG, pyloric neurons rapidly lose their ability to burst spontaneously, and the network falls silent. By using extracellular motor nerve recordings from long-term organotypic preparations of the stomatogastric nervous system of the lobster Jasus lalandii, we are investigating whether modulatory inputs exert long-term regulatory influences on the pyloric network operation in addition to relatively short-term neuromodulation. When decentralized (stn cut), quiescent STGs are maintained in organ culture, pyloric rhythmicity gradually returns within 3-5 d and is similar to, albeit slower than, the triphasic motor pattern expressed when the stn is intact. This recovery of network activity still occurred after photoinactiva-
\end{abstract}

tion of axotomized input terminals in the isolated STG after migration of Lucifer yellow. The recovery does not depend on action potential generation, because it also occurred in STGs maintained in TTX-containing saline after decentralization. Resumption of rhythmicity was also not activity-dependent, because recovery still occurred in STGs that were chronically depolarized with elevated $\mathrm{K}^{+}$saline or were maintained continuously active with the muscarinic agonist oxotremorine after decentralization. We conclude that the prolonged absence of extraganglionic modulatory inputs to the pyloric network allows expression of an inherent rhythmogenic capability that is normally maintained in a strictly conditional state when these extrinsic influences are present.

Key words: pyloric motor network; neuromodulation; stomatogastric nervous system; spiny lobster; organ culture; longterm decentralization; functional recovery
A major issue in neuroscience has been to determine the control exerted by a presynaptic neuron on its postsynaptic targets. To date, most work has focused on "conventional" synaptic influences involving transient opening of ligand-gated ion channels. In addition to this rapid-acting, short-lasting regulation, synaptic inputs also exert persistent long-term influences that play a major role in establishing and maintaining the properties of their postsynaptic targets (Thoenen and Edgar, 1982). Such long-term influences include regulation of transmitter phenotype (HyattSachs et al., 1993) and synthesis (Black and Green, 1973), receptor and gene expression (Le Moine et al., 1990; Weiser et al., 1994), and membrane excitability (Traynor et al., 1992; see below).

Demonstration of trans-synaptic influences has relied essentially on two approaches, either observing innervation-dependent changes during development or suppressing a source of synaptic input to a specified target region in the mature nervous system. The best-studied of the second of these approaches is denervation of the adult neuromuscular junction. After suppression of motor

\footnotetext{
Received Sept. 22, 1997; revised Dec. 18, 1997; accepted Dec. 22, 1997.

This work was partly supported by the Human Frontier Science Program and a doctoral studentship from the Ministère de l'Enseignement Supérieur et de la Recherche to M.T.-B. We also thank Dr. Pierre Meyrand for helpful discussions and comments on this manuscript.

Much of the impetus for this work came from Professor Maurice Moulins, who died in December 1995. We dedicate this article to his memory.

Correspondence should be addressed to Dr. J. Simmers, Laboratoire de Neurobiologie des Réseaux, Université de Bordeaux I and Centre National de la Recherche Scientifique, Place du Dr Peyneau, 33120 Arcachon, France.

Copyright (C) 1998 Society for Neuroscience $0270-6474 / 98 / 182212-14 \$ 05.00 / 0$
}

innervation, pre-existing muscle fiber ion channels proliferate and alter their distribution and kinetics (Fambrough, 1979; Beam et al., 1985; Angelides, 1986), and new channel types may appear (Lehouelleur et al., 1983; Lupa et al., 1995). In contrast to muscle cells, trans-synaptic regulation of the bioelectrical properties of central neurons, attributable in large part to the inaccessability and complexity of the networks in which they are embedded, is still poorly understood. Thus, when a neuronal assemblage is deprived of a source of innervation, any modifications in cellular properties and remaining synaptic connections are difficult to assess.

A system amenable to such investigation is the pyloric network of the crustacean stomatogastric nervous system (STNS). All 14 neurons of this network lie within the stomatogastric ganglion (STG), and it is one of the best-studied neuronal networks in which all of the constituent neurons have been identified; much about their cellular properties and synaptic interactions is known (Selverston and Moulins, 1987; Harris-Warrick et al., 1992). When the STNS is placed in vitro, the pyloric network continues to generate a rhythmic motor pattern similar to that seen in vivo (Rezer and Moulins, 1983). Although network rhythmicity arises from an interplay between synaptic connectivity and bursting properties intrinsic to the pyloric neurons (Harris-Warrick et al., 1992), the expression of these properties strictly depends on an ensemble of neuromodulatory influences arising outside the network (Moulins and Cournil, 1982; Bal et al., 1988). Thus, when STG inputs are blocked, pyloric neurons no longer burst, and the network falls silent.

The aim of the present study was to assess whether central 
modulatory inputs exert a long-term influence on the pyloric network in addition to their short-term "permissive" action on rhythmogenesis. We used extracellular motor nerve recordings from long-term organ cultures of the STNS of the Cape lobster Jasus lalandii to compare spontaneous pyloric network activity in short- and long-term decentralized STG and nondecentralized controls. We found that 3-5 d after deprivation of all neuromodulatory input, the network acquires a spontaneous rhythmogenic capability, suggesting a persistent functional recovery from elimination of some of the central nervous inputs on which network operation normally depends. This transition from "conditional" to "nonconditional" states is not related to levels of network activity, nor does it depend on the generation of intraganglionic action potentials.

Parts of this study have been published previously (Thoby and Simmers, 1997).

\section{MATERIALS AND METHODS}

All experiments $(n=48)$ were performed on adult male and female Cape lobster, Jasus lalandii, purchased from commercial suppliers (Cap Langouste, Nice, France) and kept in aquaria with fresh running seawater until used. Before dissection, lobsters were cold-anesthetized by placing them in ice for 30-45 min. Standard dissection techniques (Selverston and Moulins, 1987) were used; the isolated STNS consisted of the STG with its motor nerves, the paired commissural ganglia (CoG), the esophageal ganglion (OG), and their interconnecting nerves including the stomatogastric nerve (stn), which connects the STG to the OG and $\mathrm{CoG}$ (see Fig. 1). The STNS was pinned out on a silicone elastomer (Sylgard 184; Dow Corning)-lined Petri dish under sterile-filtered oxygenated lobster saline [composition in $\mathrm{mm}$ : $\mathrm{NaCl}, 480 ; \mathrm{KCl}, 12.75$; $\mathrm{MgSO}_{4}, 3.9 ; \mathrm{CaCl}_{2}-2 \mathrm{H}_{2} \mathrm{O}, 13.7$; and HEPES, 5; $\mathrm{pH} 7.45$ (all from Sigma, St. Louis, MO)] containing glucose $(1 \mathrm{gm} / \mathrm{l})$, penicillin $(35 \mu \mathrm{g} / \mathrm{ml})$, and streptomycin $(50 \mu \mathrm{g} / \mathrm{ml})$. The preparations were maintained at $15^{\circ} \mathrm{C}$ throughout the experiment with a laboratory-constructed cooling system, and the bathing saline, including antibiotics, was renewed daily. Under such conditions, organ cultures remained viable for 2 weeks or more.

To isolate the STG from extraganglionic inputs, we cut the stn or, in some cases, reversibly blocked descending axonal impulses by placing $10^{-7}$ M TTX (Sigma) in a Vaseline well built around a desheathed portion of the stn. To ensure the absence of impulses arising in axotomized stn fibers, we built, in several experiments, a Vaseline well around the transected stn stump and filled the well with a Lucifer yellow solution (Sigma; $10 \%$ in distilled water) that was allowed to migrate ( $>12 \mathrm{hr}$ ) into the ganglionic terminals of cut stn axons before their ablation by illumination with intense blue light (450-490 nm; Miller and Selverston, 1979).

Extracellular motor nerve recordings were made with Vaselineisolated platinum wire electrodes connected to laboratory-constructed extracellular amplifiers. In most recordings, individual motoneurons could be identified by the timing of their rhythmic bursting and/or the presence of their action potentials in known motor nerve terminal branches. Data were recorded on a Gould ES 1000 electrostatic chart recorder and simultaneously digitized (Neurocorder DR 886) and stored on magnetic tape (VHS, JVC).

\section{RESULTS}

\section{Pyloric rhythmicity depends on modulatory extraganglionic inputs}

When the STNS is placed in vitro, the pyloric network continues to generate a rhythmic motor program (Fig. $1 A$ ) similar to that recorded in the intact animal (Rezer and Moulins, 1983). This pattern consists of sequential bursts of activity in the pyloric dilator (PD), lateral pyloric (LP), and pyloric (PY) motoneurons (Selverston and Moulins, 1987; Harris-Warrick et al., 1992). A fundamental feature of the Jasus pyloric network is that it is spontaneously active in vitro only if the STG is attached to the OG and CoG (Fig. 1A). When inputs from these ganglia to the STG are eliminated by cutting the stn or by blocking stn axonal conduction with tetrodotoxin (TTX) (Fig. 1B), pyloric rhythmic- ity ceases within 10 min (seven of seven preparations tested). When the STG is functionally reconnected to the anterior ganglia by rinsing the TTX from the stn, the pyloric network again expresses its typical triphasic motor pattern (Fig. 1C). These results agree with previous reports (Moulins and Cournil, 1982; Nagy and Miller, 1987) that pyloric rhythmicity depends on unpatterned permissive inputs from the rostral centers that enable oscillatory burst-generating properties in individual pyloric neurons (Bal et al., 1988).

\section{Long-term STNS organ culture}

Because our purpose was to assess the response of the pyloric network to long-term removal of extrinsic modulatory inputs, we initially established experimental conditions under which the STNS remained viable for at least 3-5 d in vitro. This period corresponds to the time scale over which sustained changes may occur in the intrinsic properties of central neurons (Hyatt-Sachs et al., 1993; Evinger et al., 1994), including stomatogastric neurons (Panchin et al., 1993; Turrigiano et al., 1995), when deprived of synaptic influences and/or completely isolated in primary cell culture. Figure 2 shows extracellular pyloric nerve recordings from an intact STNS on the 1st, 4th, and 7th day in vitro. Robust pyloric rhythmicity continued throughout the $7 \mathrm{~d}$ period, with the only noticeable change being a gradual decrease in cycle frequency from $1.2 \mathrm{~Hz}$ on day 1 to $0.5 \mathrm{~Hz}$ on day 7. Similar observations were made from all five intact STNS preparations tested, with maximum survival periods (i.e., uninterrupted expressions of pyloric rhythmicity) of $\sim 20 \mathrm{~d}$. As seen in the pooled data of Figure $3 A$, over this period, cycle frequency decreased significantly ( $p<0.001$, paired Student's $t$ test) from a mean $( \pm \mathrm{SE})$ of $1.08 \pm 0.05 \mathrm{~Hz}$ on day 1 to $0.62 \pm 0.14$ and $0.51 \pm 0.16$ $\mathrm{Hz}$ on days 5 and 7 , respectively. This decline stabilized over subsequent days (data not shown) and probably reflected the general rundown of nervous systems operating in isolation from their normal humoral and metabolic environment.

In contrast, analysis of pyloric phase relationships revealed little quantitative changes in the pyloric pattern during long-term maintenance in organ culture. As is seen in Figure $3 B$, which was obtained from the same preparations used in Figure $3 A$, the duty cycle (mean fraction of the cycle occupied by a burst of a motoneuron) and the phase of activity of the PD, LP, and PY neurons were not significantly different on days 5 and 1 of organotypic survival.

A crucial feature of these combined in vitro STNS preparations is that expression of pyloric network rhythmicity remains strictly dependent on extrinsic modulatory inputs. This dependence, which was seen in five of five preparations, is illustrated in Figure 4 in which an isolated combined STNS produced uninterrupted pyloric rhythmicity during a $7 \mathrm{~d}$ period in culture (Fig. 4A). However, as seen for freshly dissected STNS (see Fig. 1), this preparation immediately (Fig. 4B) and reversibly (Fig. 4C) fell silent when decentralized by blocking stn impulse traffic with TTX. This experiment also argues against a significant contribution to rhythmogenesis from axotomyinduced changes in the bioelectrical behavior of pyloric motoneurons, as found in other motor systems (Goodman and Heitler, 1979; Kuwada and Wine, 1981), or from a nonspecific action of the antibiotics in the bathing saline. For example, penicillin induces epileptogenic oscillations and burst firing in central neurons (Meyer and Prince, 1973) and motoneurons (Veskov et al., 1989). Replacing penicillin with an alternative antibiotic, gentamycin $(50 \mu \mathrm{g} / \mathrm{ml})$, had no effect on the ability 


\section{A- stn intact}

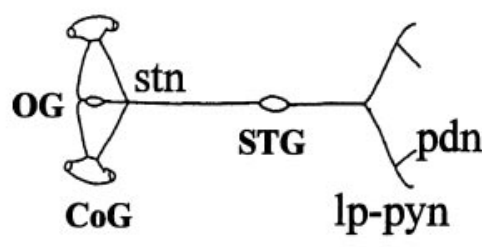

lp-pyn

pdn
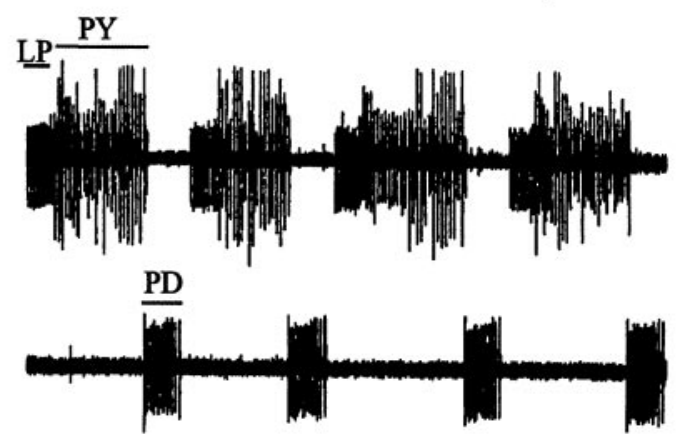

\section{B- stn blocked}

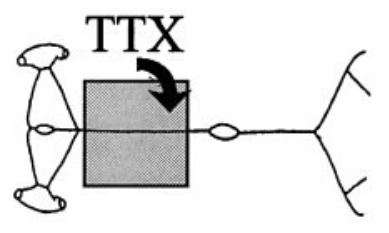

lp-pyn

pdn

\section{C- block removed}

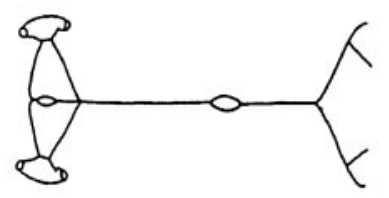

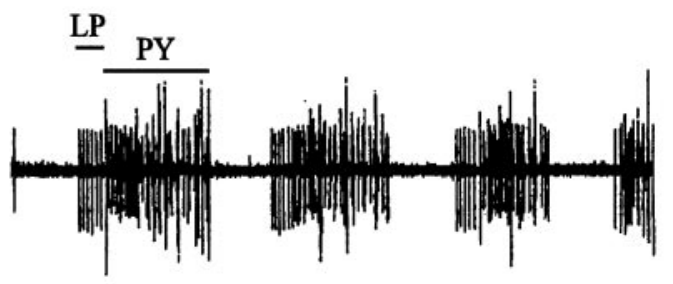

pdn

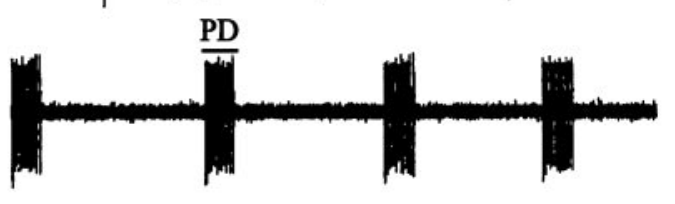

$1 \mathrm{~s}$

Figure 1. Expression of lobster pyloric network activity depends on descending modulatory inputs. $A$, Pyloric neural output from a combined STNS preparation (schema at left) consisting of the $S T G$ connected via the stn to the CoG and $O G$. Motor nerves recorded are the lp-py nerve (lp-pyn), which carries $L P$ and $P Y$ motoneuron axons, and the pd nerve $(p d n)$, which contains $P D$ neuron axons. $B$, Complete absence of spontaneous rhythmic activity in the same preparation $30 \mathrm{~min}$ after axonal conduction in the $\operatorname{stn}$ was blocked with tetrodotoxin $\left(10^{-7} \mathrm{M}\right)$ placed in a Vaseline well around the $\operatorname{stn}$ (schema at left). C, Spontaneous rhythmic activity reappearing minutes after the STG is functionally reconnected to the rostral ganglia by rinsing the toxin from the stn (schema at left).

of combined STNS preparations to remain continuously active in vitro.

\section{Recovery of pyloric rhythmicity in long-term isolated STG}

To follow the response of the pyloric network to prolonged removal of central modulatory inputs, we placed combined STNS preparations in culture and then cut the stn to eliminate immediately input from the rostral ganglia. One such experiment is illustrated in Figure 5, in which the same pyloric nerves were monitored before (Fig. $5 A$ ) and on a daily basis for $4 \mathrm{~d}$ after (Fig. $5 B$ ) stn transection. As seen previously (Fig. 1) and consistent with its dependence on extrinsic modulatory inputs, the network 


\section{A- Day 1}

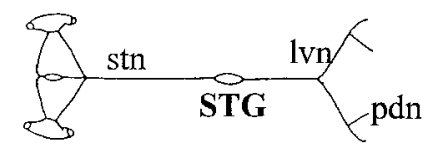

$\operatorname{lvn}$

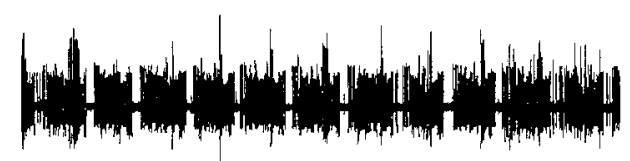

$\operatorname{pdn}$

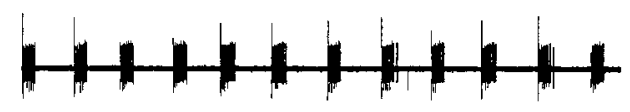

\section{B- Day 4}

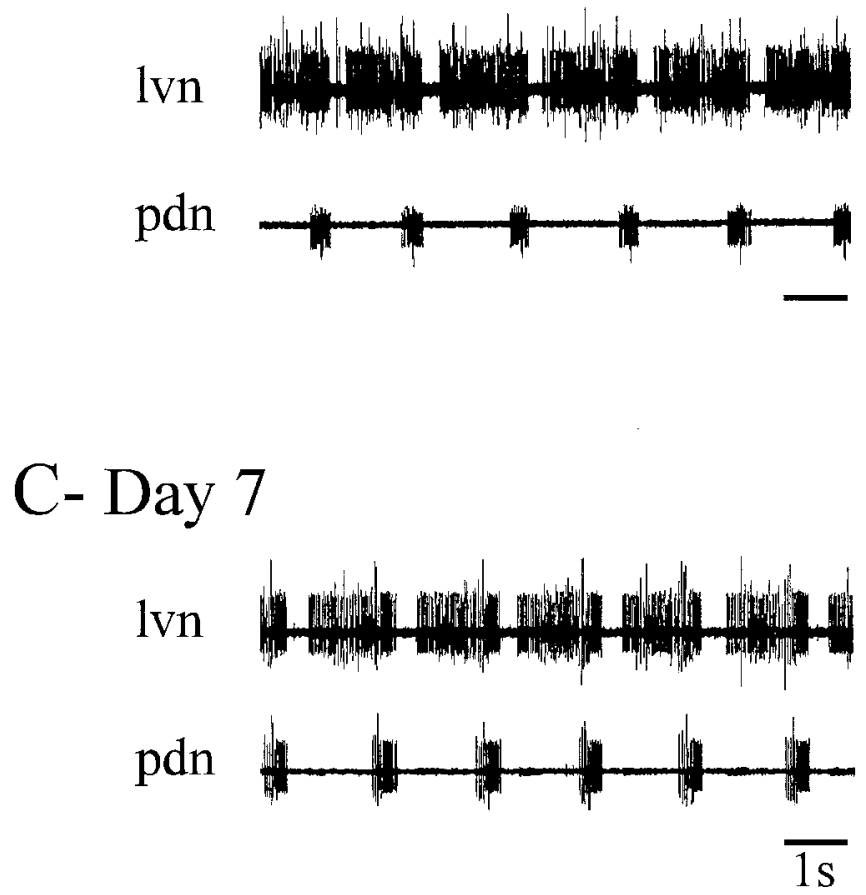

Figure 2. Spontaneous pyloric output from an intact STNS during longterm organ culture in vitro. $A$, Day 1 . Rhythmic pyloric network activity recorded extracellularly from the lateral ventricular nerve (lvn; top trace) and the pdn (bottom trace) of an intact isolated STNS (schema). B, Day 4. Same preparation and nerve recordings after $4 \mathrm{~d}$ in vitro. $C$, Day 7. Same preparation and nerve recordings after $7 \mathrm{~d}$ in vitro. Although the rhythm has slowed, the pyloric network is still spontaneously active.

fell silent soon after STG decentralization (Fig. 5Bi). In some experiments $(n=8)$, transection was performed on stn in which impulses were blocked previously with locally applied TTX. This procedure, which was used to avoid stn axon injury discharge (and hence transmitter release by stn fiber terminals in the STG), decreased the time it took for the pyloric network to fall quiescent but did not otherwise alter the initial inability of the network to operate without intact rostral inputs.

In contrast to the total silence of the pyloric network during the
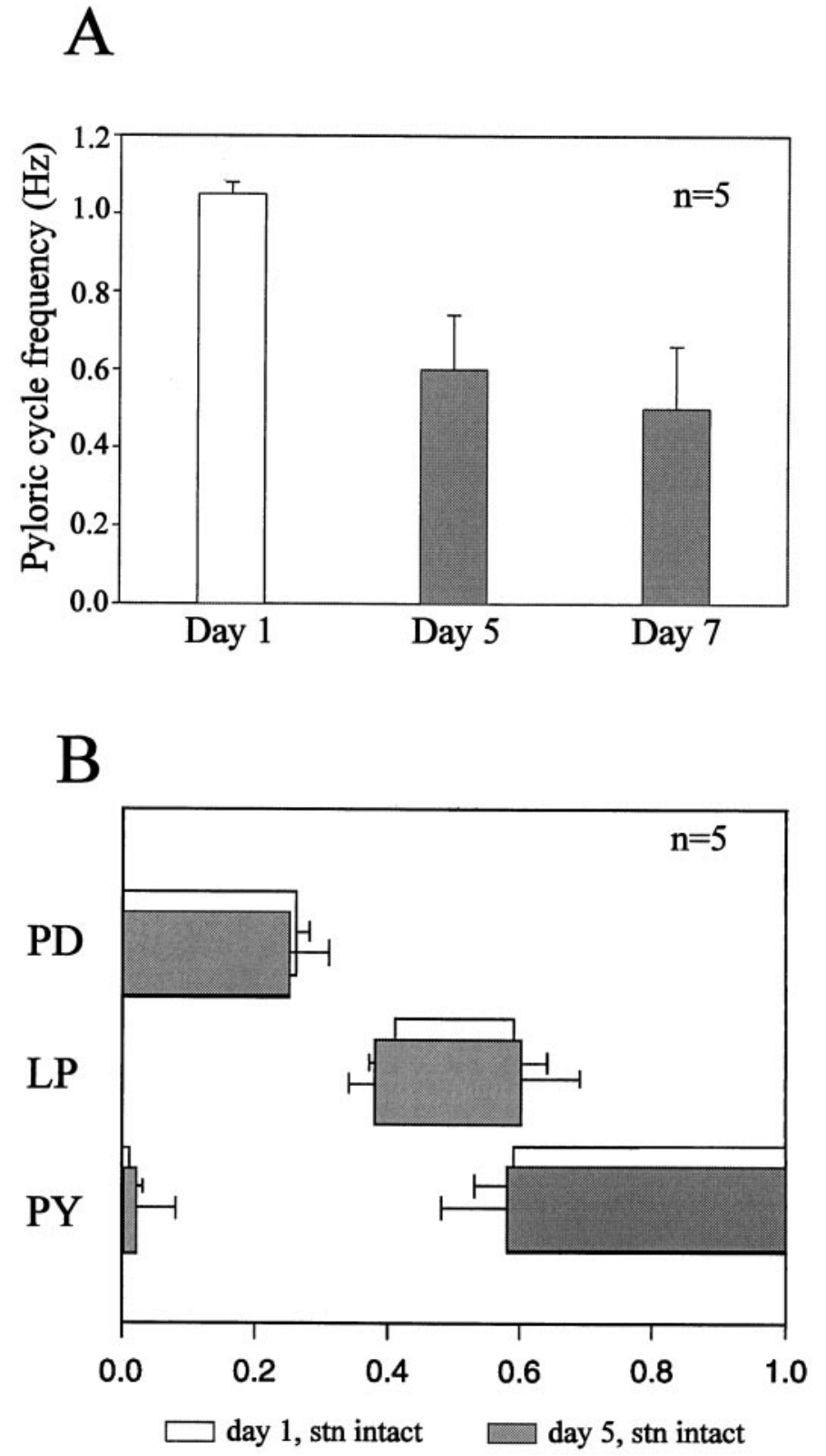

Figure 3. Evolution of pyloric cycle frequency and phasing of motor bursts in long-term STNS preparations in which the STG remained connected to the rostral ganglia. $A$, Mean cycle frequency $( \pm \mathrm{SE})$ of spontaneous pyloric rhythmicity in five combined STNS preparations at days 1,5 , and 7 in organ culture. The preparations were continuously active throughout the experiment, although cycle frequency gradually decreased. Each histogram was derived from at least 50 consecutive cycles per preparation. $B$, Phase relationships of the pyloric motoneurons on day 1 (clear boxes) and day 5 (shaded boxes) in vitro. The beginning and end of each box represent the mean $( \pm \mathrm{SE})$ onset and offset phases of the burst of the indicated neuron; one cycle is shown. Results are from the same preparations used in $A$. Pyloric network phase relationships did not change significantly (paired Student's $t$ test) in organ culture.

first $2 \mathrm{~d}$ after stn transection (Fig. 5Bi,ii), pyloric activity gradually reappears from the 2 nd or 3 rd day. This restoration initially consists of tonic firing or slow irregular motoneuron bursting (Fig. 5Biii), but by the 4th or 5th day (Fig. 5Biv), the spontaneous rhythm is similar to, albeit slower than (but see below), the pattern seen originally when the stn was intact (compare Fig. $5 A$ ). To follow more precisely the time course of this reacquisition of 


\section{A- Day 7, stn intact}

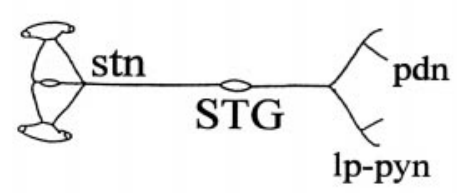

lp-pyn lpn

pyn

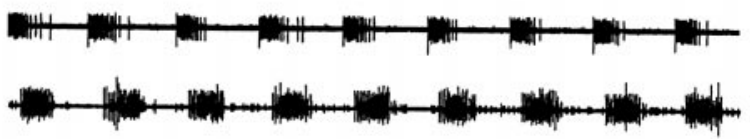

pdn

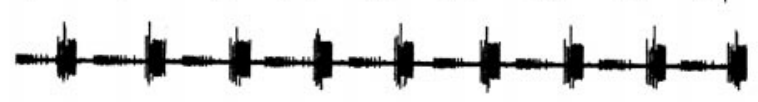

\section{B- Day 7, stn blocked}

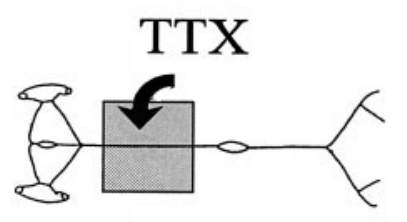

lpn

pyn

pdn

\section{C- Day 7, block removed}
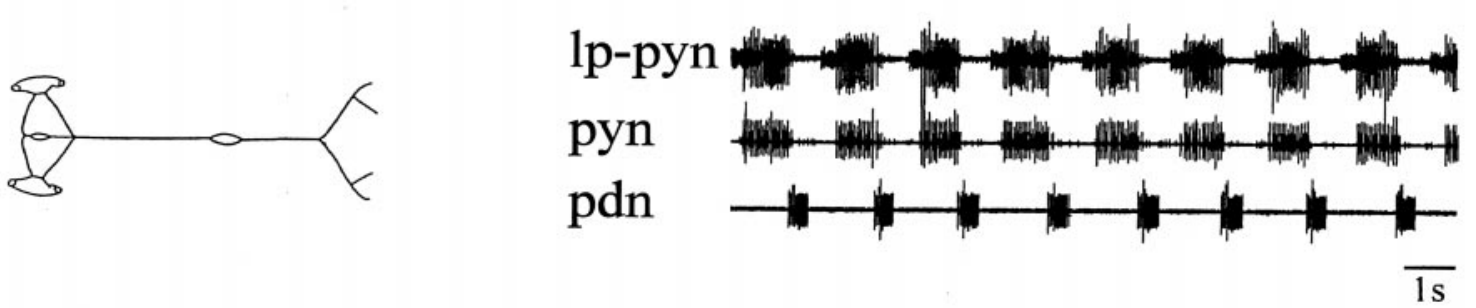

Figure 4. Pyloric network activity of a combined STNS remains conditional on functional stn inputs throughout long-term organ culture. $A$, Spontaneous rhythmic activity (right) was recorded extracellularly from pyloric motor nerves of an isolated STNS (left) in which the STG remained attached to the three rostral ganglia after $7 \mathrm{~d}$ in organ culture. B, Pyloric activity ceases (right) soon after disconnection of the STG from the three rostral ganglia by the application of $10^{-7} \mathrm{M}$ TTX to the stn $(l e f t)$. C, Pyloric activity returns (right) after the blockade of stn axonal conduction was removed $(l e f t)$.

pyloric rhythmicity in decentralized STGs, we recorded from five preparations on successive days after placement in culture and stn transection. Pooled measurements of mean pyloric cycle frequency $( \pm \mathrm{SE}$ ) from days 1 to 7 are shown in Figure $6 A$. After $1-2$ $\mathrm{d}$ in culture, little or no spontaneous activity was expressed by all preparations. On day 3 , slow pyloric activity appeared, and on day 5 , the frequency of this activity abruptly and significantly $(p<$ 0.001 , paired Student's $t$ test) increased (mean frequency, $0.07 \pm$ $0.02 \mathrm{~Hz}$ on day 4 and $0.37 \pm 0.19 \mathrm{~Hz}$ on day 5$)$, after which cycle frequency stabilized $(0.43 \pm 0.15 \mathrm{~Hz}$ on day 7$)$. Note that although the cycle frequencies of these recovered pyloric rhythms were some $60 \%$ less than were those on day 1 before decentralization (compare Fig. 3A, Day 1), these values were comparable with the cycle frequencies of 5 and $7 \mathrm{~d}$ in vitro preparations with intact stns (compare Fig. 3A, Day 5, Day 7). Resumption of pyloric rhythmicity was observed in $84 \%$ of 15 isolated STG preparations, and in each case in which it occurred, rhythmicity was expressed for the remaining preparation survival time (maximum $15 \mathrm{~d}$ ).

Phase relationships of the three main classes of pyloric motoneuron after rhythm recovery (on day 5) are shown in Figure $6 B$ (data are pooled from the same preparations used in Fig. $6 A$ ). For comparison, the phase and duty cycle of the neurons before decentralization (on day 1) are also illustrated. For the PD and LP neurons, the duty cycle differed little in the two experimental situations, although the LP neuron-burst onset and offset occurred relatively earlier in each cycle of the recovered rhythm. For the PY neurons, the duty cycle increased significantly (by $15-20 \%$ ) as a result of their bursts beginning earlier in the cycle. As a consequence, the overlap between LP neuron-burst termination and PY neurons-burst onset remained constant.

In summary to this point, therefore, after several days in vitro, the pyloric network is capable of functional recovery from the loss of central inputs on which its activity normally depends. 


\section{A- stn intact}
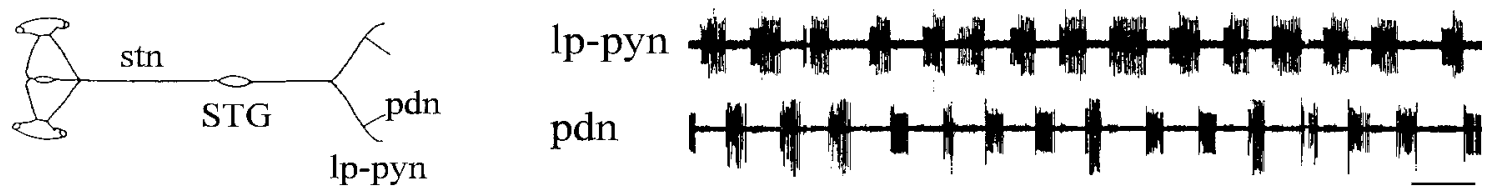

\section{B- stn cut}

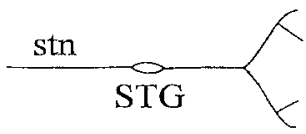

i) $+24 \mathrm{hr}$

lp-pyn

pdn

ii) $+48 \mathrm{hr}$

iii) $+72 \mathrm{hr}$

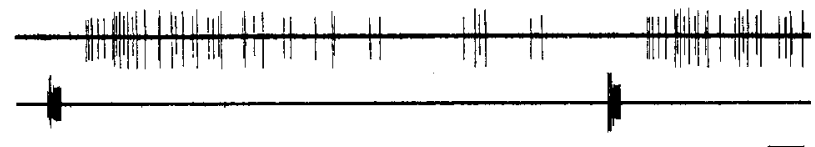

iv) $+96 h r$

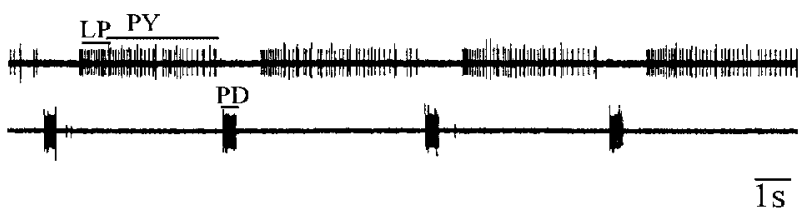

Figure 5. Functional recovery of pyloric network activity during long-term organ culture of a decentralized STG. $A$, Pyloric rhythmicity in a freshly dissected, intact STNS (schema at left). Motor nerves recorded are the lp-pyn and the $p d n$. B, Same preparation and recordings made at daily intervals after cutting the stn (schema at left). There is a complete absence of pyloric network activity on the 1st $(i)$ and 2 nd (ii) day after suppressing STG inputs. By the 3rd day (iii) after stn transection, a slow spontaneous rhythm emerges. By the 4th day after stn section (iv), the decentralized pyloric network expresses a more robust rhythm that, although still slower than the control pattern (compare $A$ ), consists of strongly coordinated bursting in the three pyloric motoneuron classes $(L P, P Y$, and $P D)$.

Although the re-established rhythm is slower and somewhat different in terms of the timing and relative contribution of individual neuron bursts to each cycle, basic features of the normal triphasic pyloric motor pattern are strictly maintained.

\section{Recovery is not caused by continued activity in} axotomized afferent terminals

Because regeneration of severed stn axons was not possible in our in vitro experiments, re-establishment of normal interganglionic pathways (Cohen et al., 1986) cannot be responsible for the reacquisition of pyloric rhythmicity in long-term isolated STG. In contrast, similar to crustacean axons in general (Bittner, 1988), axotomized fiber terminals in the stn stump are slow to degenerate (Royer, 1987). Thus, the possibility arises that these residual input processes begin to generate action potentials and to liberate transmitter and so to contribute to the restoration of pyloric rhythmicity. However, this hypothesis can be rejected for the 


\section{A}

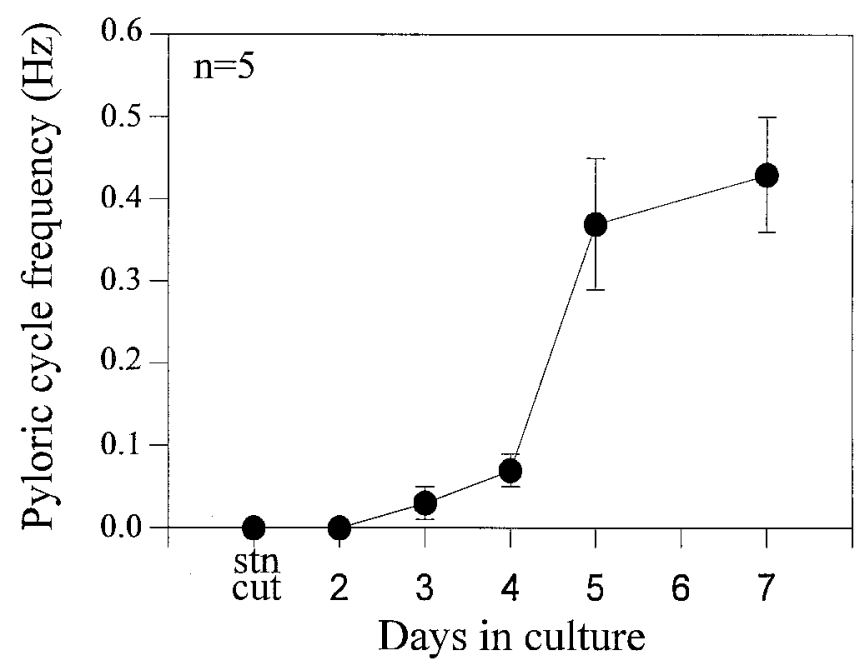

B

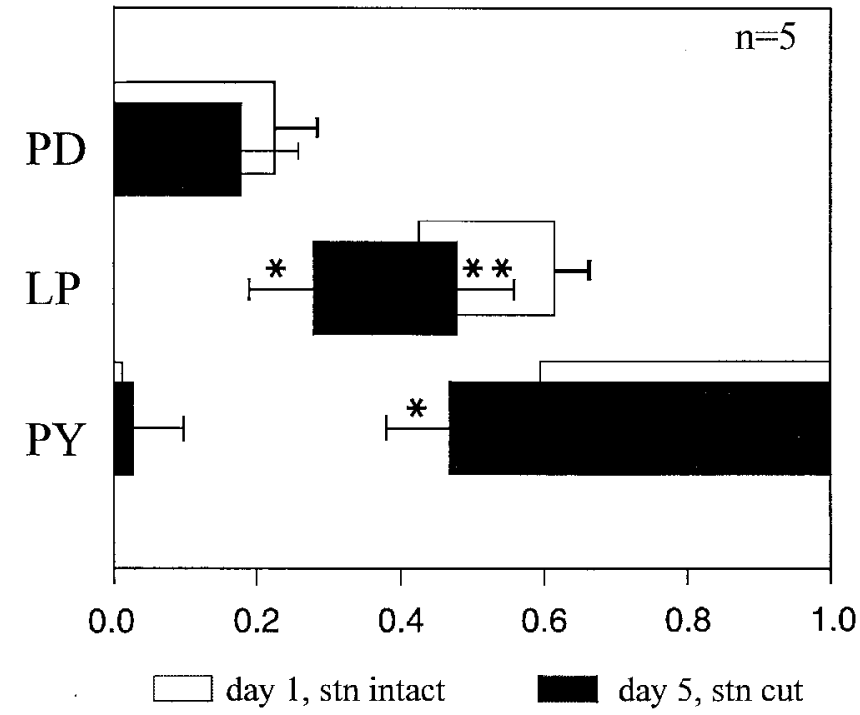

Figure 6. Evolution of pyloric cycle frequency and phasing in long-term decentralized STGs in vitro. $A$, Mean pyloric cycle frequency $( \pm \mathrm{SE})$ of five STGs during the $7 \mathrm{~d}$ after decentralization. Each point was derived from at least 50 consecutive cycles (when rhythmicity was expressed) per preparation. $B$, Phase relationships of the same neurons on day 1 before decentralization (clear boxes) and in recovered rhythms $4 \mathrm{~d}$ after decentralization (black boxes). Data are from the same preparations used in $A$. Onset and offset phases before and after decentralization were compared using a paired Student's $t$ test $(* p<0.05 ; * p<0.01)$.

following reasons. First, whereas blockade of stn impulses with focally applied isotonic sucrose or TTX always caused cessation of pyloric activity $(n=7)$ in control combined preparations, similar treatment of the stn stump of recovered long-term $(>3 \mathrm{~d})$ isolated STGs $(n=8)$ never interrupted ongoing rhythmicity (data not shown). It is also noteworthy that sucrose or TTX applied to a desheathed portion of the primarily efferent nerve leading to the lvns similarly failed $(n=3)$ to disturb recovered pyloric rhythmicity. In a complementary experiment $(n=2)$, a TTX block placed on this nerve throughout the entire $3 \mathrm{~d}$ after STG decentralization also did not affect reacquisition of the pyloric rhythm. Together these observations suggest that activity occurring in STG afferent fibers in this nerve (Katz and HarrisWarrick, 1989) is also not participating in rhythm recovery.

Second and most compellingly, experimental ablation of axotomized fibers in the stn stump did not prevent the reacquisition of pyloric rhythmicity. One of eight such preparations is shown in Figure 7. For this experiment, a control combined STNS was set up and recorded (Fig. $7 A$ ), then the stn was cut, and a $10 \%$ aqueous solution of Lucifer yellow was placed in a Vaseline well built around the transected stn stump (Fig. 7B). After orthograde migration of the dye in the severed stn axons during the subsequent $18 \mathrm{hr}$, the staining of afferent projections within the ganglionic neuropile was verified directly under a fluorescence microscope, and then the dye-filled terminals were photoinactivated by exposure for $10-15 \mathrm{~min}$ to intense blue light (Miller and Selverston, 1979).

Two criteria for successful ablation of STG input terminals were used: (1) an intense activation of pyloric neurons during STG illumination (Fig. 7C), indicating depolarization-induced transmitter release from dying input axon terminals, and (2), after the network fell silent after photoinactivation (Fig. 7Di), insensitivity to electrical stimulation applied to the stn stump (see below). It should be noted that backfilling the stn unavoidably stains a small number of neurons that have cell bodies located in the STG and that send their axons away from the ganglion in the stn. Because one of these cells is the unique interneuron of the pyloric network, the anterior burster $(\mathrm{AB})$ interneuron, this cell was necessarily deleted from the network. [Direct intrasomatic recordings to be reported in a subsequent paper confirmed that the $\mathrm{AB}$ neuron was killed by this procedure (M. Thoby-Brisson and J. Simmers, unpublished observations).] Despite these conditions, however, reacquisition of pyloric rhythmicity still occurred with approximately the same time course as before, attaining full recovery $5 \mathrm{~d}$ after stn transection (Fig. $7 D$ ). As seen previously (Figs. 5, 6A), the process again followed a gradual transition from complete silence (Fig. 7Di), via tonic (Fig. 7Dii) and weakly rhythmic (Fig. 7Diii) activity, to a robust triphasic pattern on the 3rd day after photoinactivation (Fig. 7Div). Functional recovery of a long-term decentralized pyloric network therefore does not require an intact network, nor evidently does it depend on the survival of axotomized input terminals.

A major concern in these ablation experiments is the extent to which stn input axons, especially the finer fibers, were successfully labeled by the dye and killed by the photoinactivation procedure. Although we cannot verify that all afferent axons were eliminated, in three control experiments, extracellular stn stimulation before and after photoinactivation strongly suggested that a significantly large proportion of the modulatory terminals were effectively removed. One such experiment is shown in Figure 8, in which a $1 \mathrm{sec}$ electrical stimulation of the stn elicited pyloric rhythmicity from an otherwise silent decentralized STG soon after stn transection (Fig. $8 A$ ) and, similarly, after washout with normal saline after $18 \mathrm{hr}$ of Lucifer yellow migration into the input nerve stump (Fig. 8Bi). In contrast to this continued activation after the backfill, repeating the stimulation $\sim 3 \mathrm{hr}$ after STG illumination now failed completely to elicit the pyloric rhythm (Fig. 8Bii). This lack of responsiveness to stn stump stimulation, which was sustained for the longevity of the preparation, persisted with increasing strengths of stimulation, after placing the electrode closer to the ganglion and even after recutting the nerve at its point of entry to the ganglion (data not shown). Thus although survival of some axotomized terminals 
A- Day 1, stn intact

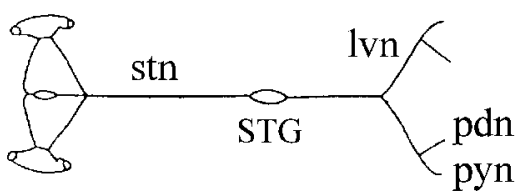

Di- Day 2

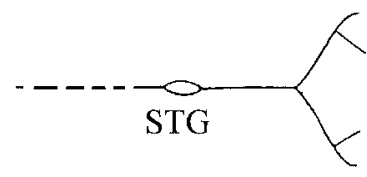

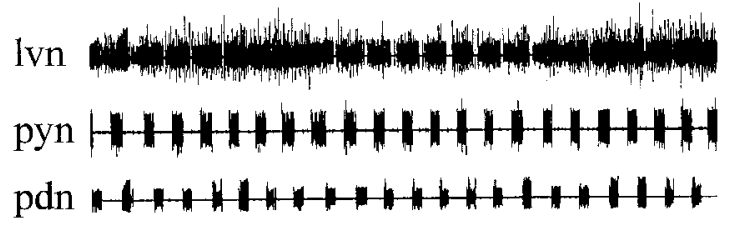

B- Day 1, stn cut

Lucifer Yellow

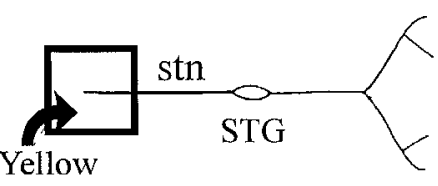

\section{C- Day 2, photoinactivation}
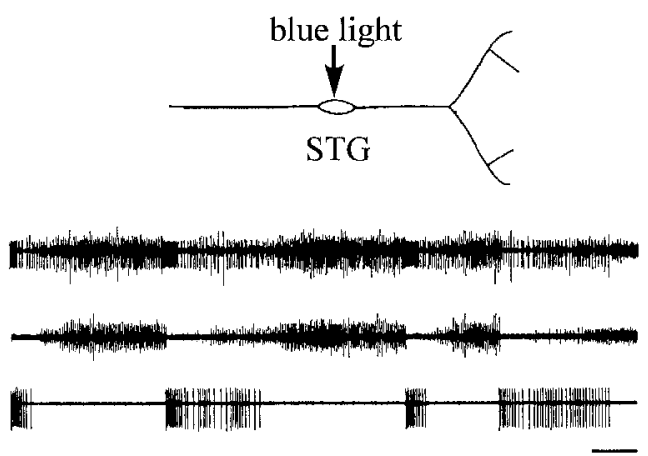

\section{ii- Day 3}

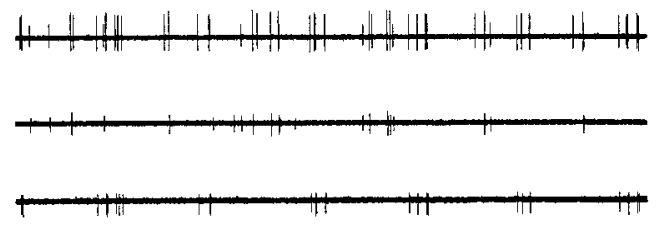

\section{iii- Day 4}

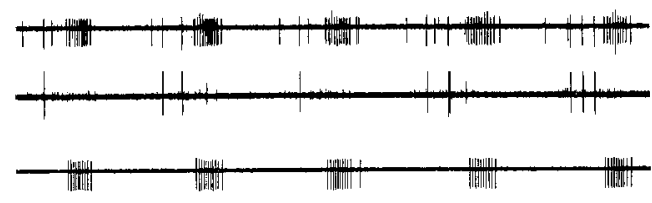

\section{iv- Day 5}

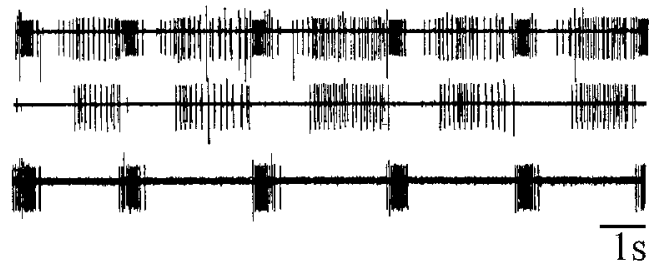

Figure 7. Recovery of pyloric network rhythm after photoinactivation of stn input terminals. $A$, Spontaneous pyloric output from a freshly dissected combined STNS is shown. Extracellular recordings are from the lvn and from distal branches carrying the PY and PD neuron axons (schema). B, Pyloric rhythm ceases after cutting the stn. A Vaseline well filled with Lucifer yellow was placed around the cut stn stump (schema) to dye-fill axons into the STG. $C$, After $18 \mathrm{hr}$ of dye migration, STG illumination with blue light (schema) transiently activates the pyloric network during photoinactivation of dye-filled terminals. $D i$, The absence of any activity in the same preparation $2 \mathrm{hr}$ after photoinactivation of stn inputs (schema) is shown. Dii-Div, Recordings from the same nerves shown in $A-D i$, at days 2 (Dii), 3 (Diii), and 4 (Div) after the original decentralization, show gradual recovery of spontaneous triphasic pyloric rhythmicity.

remains possible, it is difficult to see how these projections alone could be responsible for the subsequent recovery of network activity in long-term STG culture.

\section{Recovery of rhythmicity in a silent STG}

Because residual extrinsic inputs to the pyloric network do not seem to underlie the resumption of rhythmicity, we examined whether this process required impulse-driven signaling within the network itself. To test this possibility, we incubated long-term decentralized STGs in TTX-containing saline to block fast sodium channels and hence prevent generation of action potentials. One such experiment is illustrated in Figure 9, in which the spontaneous pyloric rhythm in a freshly dissected combined 


\section{A- Day 1, stn cut $+2 \mathrm{hr}$}

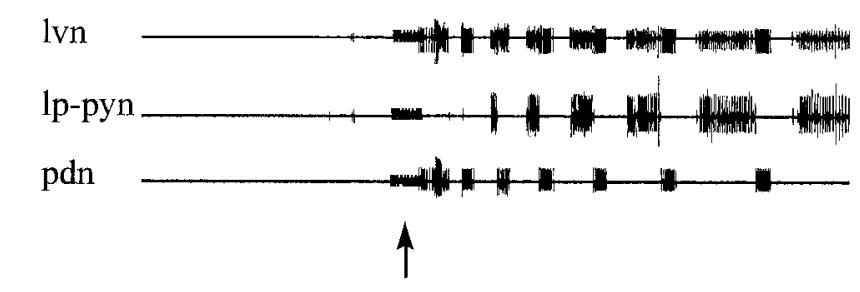

B- Day 2 , stn cut $+18 \mathrm{hr}$

i) pre-photoinactivation

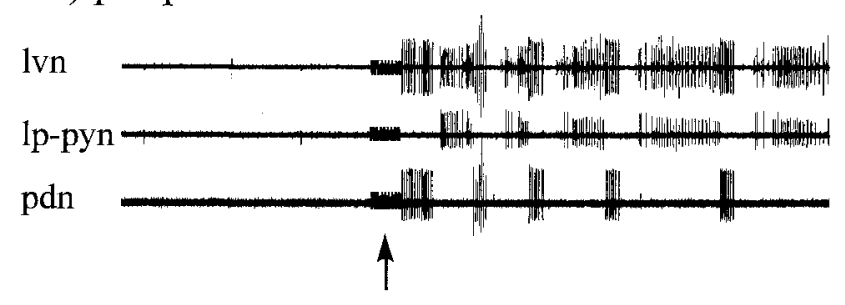

ii) post-photoinactivation

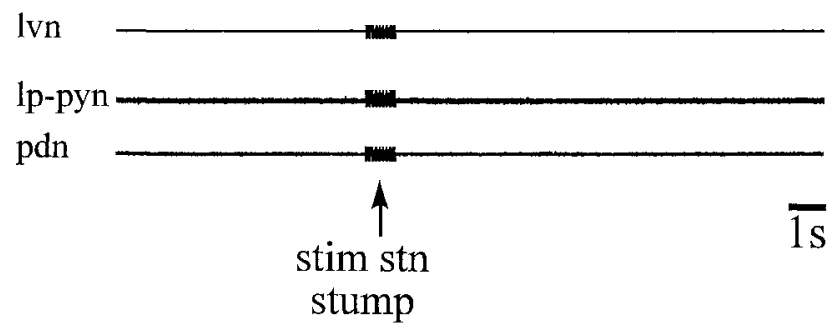

Figure 8. Test for photoinactivation of stn input terminals in the STG. A, Extracellular electrical stimulation $(10 \mathrm{~Hz}$ for $1 \mathrm{sec}$ at arrow $)$ of the stn stump evokes pyloric activity in an otherwise quiescent STG, $2 \mathrm{hr}$ after cutting the stn. $B$, Same preparation $\geq 18 \mathrm{hr}$ after stn labeling with Lucifer yellow is shown. Stimulation (arrows) of the stained input nerve (now bathed in normal saline) again elicits pyloric rhythmicity $(i)$ but has no effect $\approx 3 \mathrm{hr}$ after illuminating the ganglion (ii). Increasing the stimulus intensity or resectioning the stn stump similarly had no effect.

STNS was first recorded (Fig. 9A), then the stn was cut, and the preparation was rendered completely silent by adding $10^{-7} \mathrm{M}$ TTX to the bathing saline (Fig. 9B). (Intracellular recordings also verified that individual pyloric neurons did not continue to oscillate without spikes and interact via graded synaptic transmission.) After $4 \mathrm{~d}$ under such conditions (with the TTX replenished daily along with antibiotic), the toxin-containing saline was rinsed (requiring at least $6 \mathrm{hr}$ ) from the ganglion until action potentials were again expressed. In 10 out of 12 such experiments, the termination of long-term TTX exposure was accompanied by the expression of a strongly active pyloric rhythm (Fig. 9C) that again displayed all the main features of the pattern seen before decentralization (compare Fig. $9 A$ with $C$ ). These observations therefore support the earlier conclusion that functional recovery of the decentralized pyloric network is not caused by continued discharge in axotomized input terminals and also indicate that the recovery process does not require electrical activity within the ganglion itself.

\section{Recovery of rhythmicity in an active STG}

Finally, we wished to assess whether rhythm recovery was because of a direct, intrinsic response of pyloric network neurons whereby they compensated for their diminished levels of activity after decentralization to become rhythmically bursting (LeMasson et al., 1993; Turrigiano et al., 1994). If this was the case, then a network that was forced to remain active after isolation from extrinsic inputs would be expected to display a diminished capacity for subsequent functional recovery. In a first step to test this possibility, we increased pyloric neuron activity after decentralization by elevating the extracellular potassium ion concentration (Franklin et al., 1992; Berdan et al., 1993). Specifically, isolated ganglia $(n=4)$ were incubated for $3 \mathrm{~d}$ after decentralization in saline containing twice $(25 \mathrm{~mm})$ the normal $\mathrm{K}^{+}$concentration. $\left[\mathrm{A}\left[\mathrm{K}^{+}\right]\right.$increase of this order causes pyloric lobster stomatogastric neurons to depolarize 5-10 $\mathrm{mV}$ (M. Thoby-Brisson and J. Simmers, unpublished observations).] As is shown in Figure 10, exposure of a newly decentralized, silent STG (Fig. 10A) to high $\mathrm{K}^{+}$saline caused a pyloric pattern to reappear (Fig. 10Bi) within minutes of the onset of superfusion. Presumably this rhythm, which was slower and less regular than normal, was triggered by nonspecific stimulation of the STG via the potassium depolarization. After $4 \mathrm{~d}$ further exposure to these conditions (Fig. 10Bii), the still-active decentralized ganglion was returned to normal (12 $\mathrm{mm}) \mathrm{K}^{+}$saline, and the pyloric motor nerves were again recorded some 1-2 hr later. The robust and regular activity seen in Figure $10 C$, which was observed in all four isolated ganglia up to $24 \mathrm{hr}$ after return to control saline, suggests that prolonged potassium depolarization does not significantly impair the capacity of the pyloric network to recover rhythmicity.

In a parallel set of experiments, we used specific pharmacological stimulation with oxotremorine $\left(10^{-5} \mathrm{M}\right)$, a muscarinic agonist known to induce pyloric rhythmicity in the isolated lobster STG (Bal et al., 1994), to sustain pyloric network activity throughout the $4 \mathrm{~d}$ period after decentralization. The results of one such experiment are shown in Figure 11. Again, the pyloric rhythm in a combined STNS disappeared after cutting the stn (Fig. 11 $A$ ) but was immediately and powerfully restored (Fig. $11 B$ ) by superfusing the STG with oxotremorine $\left(10^{-5} \mathrm{M}\right)$. During the ensuing $3 \mathrm{~d}$, the bath saline containing the oxotremorine was renewed daily, and the preparation was monitored to verify uninterrupted pyloric activity (data not shown). The STG was then rinsed with normal saline for $24 \mathrm{hr}$ and again recorded, now $5 \mathrm{~d}$ after the initial dissection (Fig. 11C). Here again, because robust rhythmicity was still expressed after removal of the agonist, the simplest interpretation is that, in our organ cultures, rhythm recovery is not deriving solely from an activity-dependent, homeostatic adjustment of excitability by individual pyloric neurons. Results similar to those shown in Figure 11 were obtained from all five oxotremorine-treated STGs tested.

\section{DISCUSSION}

In this paper we have shown that, whereas short-term suppression of modulatory inputs to the stomatogastric ganglion causes immediate cessation of pyloric network activity, after 3-5 d in organ culture the decentralized network reacquires the ability to generate a spontaneous motor pattern similar to that expressed when the input stn was intact. This indicates that prolonged absence of a population of, as yet unidentified, modulatory inputs to the 


\section{A- Day 1, stn intact}

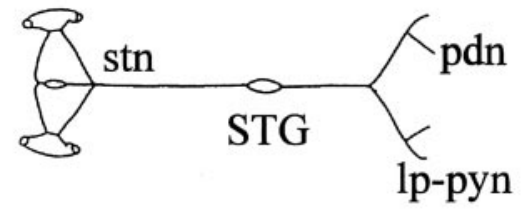

lp-pyn

pdn

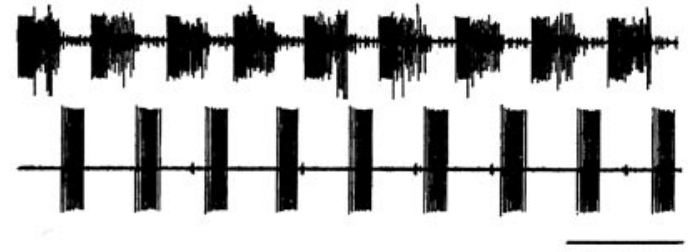

lp-pyn

pdn

\section{C- Day 5, TTX rinsed}

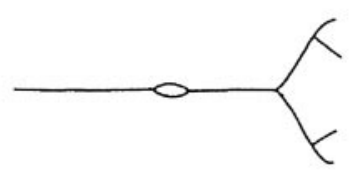

lp-pyn

pdn

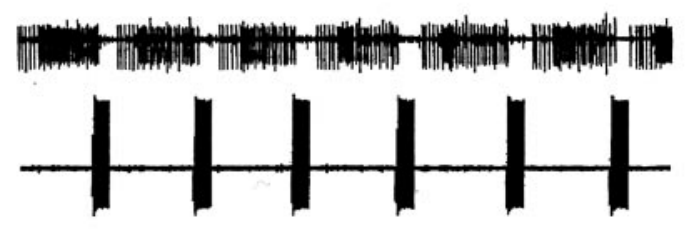

$\overline{1 s}$

Figure 9. Recovery of pyloric rhythmicity in a decentralized, long-term silent STG. $A$, Spontaneous pyloric pattern (right) recorded from the $l p-p y n$ and the $p d n$ of a freshly dissected combined STNS preparation (left) under normal saline. B. Total absence of activity in the same nerves (right) after the stn was cut in the presence of TTX $\left(10^{-7} \mathrm{M}\right)$ in the bathing saline $(l e f t)$. The decentralized, silent preparation was maintained under these conditions during the following $4 \mathrm{~d}$. C, Pyloric motor pattern (right) expressed on day 5, $6 \mathrm{hr}$ after rinsing the toxin from the decentralized STG (left).

pyloric network allows the expression of an intrinsic rhythmogenic capability that is normally maintained in a strictly conditional (modulation-dependent) state by these same extrinsic influences.

What is the stimulus for this alteration in chemosensitivity of the isolated network? When the STG is placed in organ culture, the pyloric network neurons are not only decentralized but also are themselves axotomized as well as exposed to a chemical environment totally different from that experienced in vivo. The importance of changes in humoral environment is difficult to assess. For example, certain downregulatory factors, such as specific circulating hormones, that may sustain network chemodependence in vivo are undoubtedly missing in our in vitro conditions. Alternatively, stimulatory factors, such as the unavoidable use of antibiotic in the organ culture medium, could play a nonspecific role in rhythm recovery (Meyer and Prince, 1973; Veskov et al., 1989), although our finding that long-term stn intact in vitro preparations immediately fell silent with subsequent stn blockade argues against this possibility.

Axotomy is well known to evoke a variety of changes in the intrinsic character of neurons, such as increasing somatic excitability (Goodman and Heitler, 1979; Kuwada and Wine, 1981) and altering the expression of neurotransmitters (Hyatt-Sachs et al., 1993) and receptors (Jacob and Berg, 1987). Here again, however, the inability of the isolated STNS to sustain pyloric rhythmicity after STG decentralization after several days in vitro suggests that pyloric motoneuron axotomy does not make a substantial contribution to rhythm recovery. A further argument that 


\section{A- Day 1, stn cut}

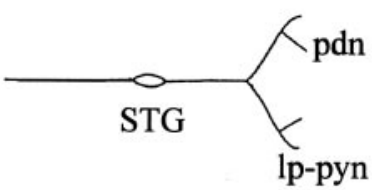

\section{B- High $\mathrm{K}^{+}$}

\section{i) Day 1}

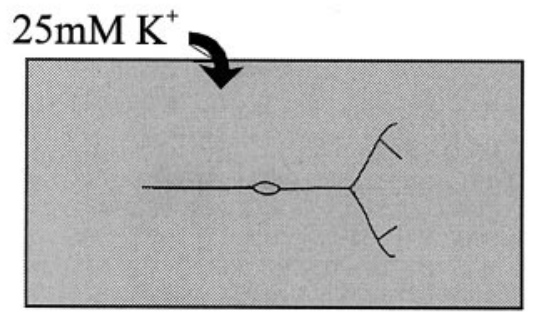

\section{ii) Day 5}

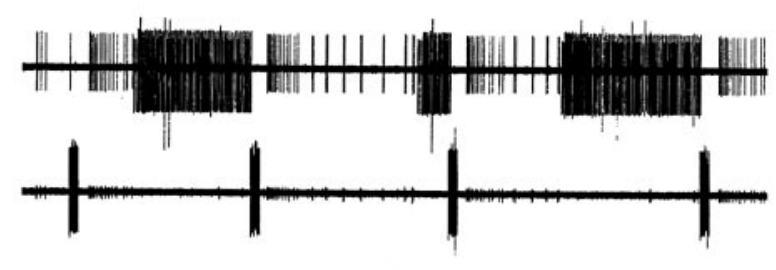

pdn

pdn

lp-pyn

lp-pyn

pdn

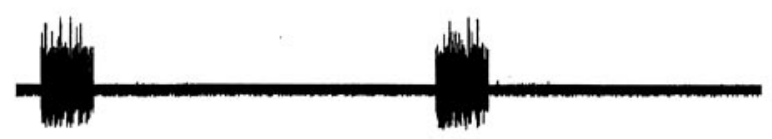

\section{C- Day 5, normal K ${ }^{+}$}
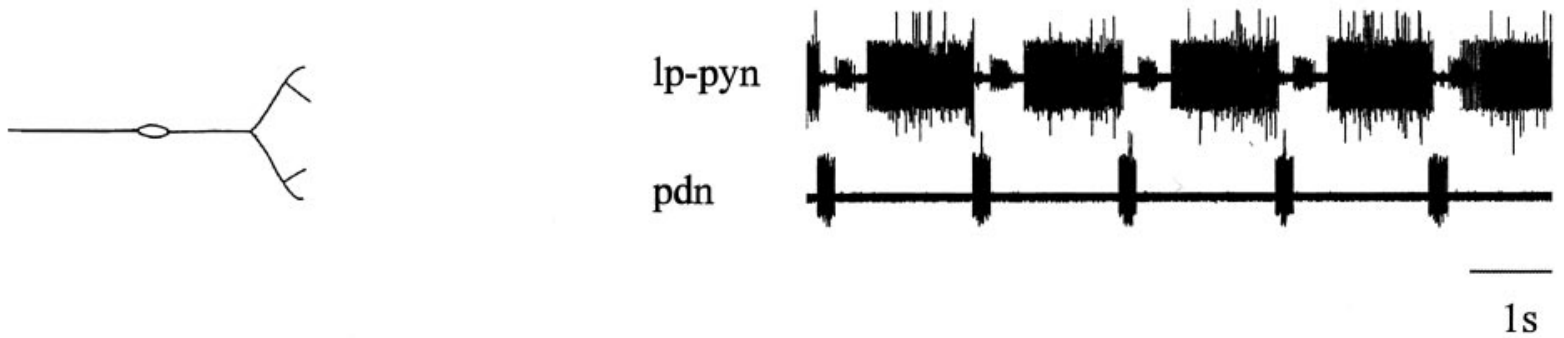

Figure 10. Recovery of pyloric rhythmicity in a decentralized, chronically depolarized STG. $A$, Absence of rhythm (right) in a freshly dissected STNS after cutting the stn in normal saline (left). Recordings are from the lp-pyn and the $p d n$. B, Activation of the rhythm (right) by superfusion of elevated $(25 \mathrm{~mm}) \mathrm{K}^{+}$saline $(i$, left), which was replenished daily over the following $4 \mathrm{~d}$. Recordings are from the same nerves used in $A$ on days 1 ( $i$ ) and 5 (ii) of high $\mathrm{K}^{+}$exposure. $C$, Robust spontaneous pyloric rhythm on day 5 (right), 1-2 hr after rinsing the preparation with normal (12 mM) $\mathrm{K}^{+}$saline (left).

axotomy-induced plasticity is insufficient to account for pyloric rhythm recovery in organ culture derives from experiments in which the STG was decentralized (with its efferent nerves left intact) in vivo (J. Simmers and E. Rezer, unpublished observations; see also Rezer and Moulins, 1992). In all cases in which the stn had been cut in situ (from 1 week to 12 months), robust pyloric rhythmicity continued to be expressed by the decentralized STG when freshly dissected from the animal. Importantly, moreover, these ex vivo experiments confirm that the recovery of rhythmicity occurring in our organ culture experiments represents a long- 


\section{A- Day 1, stn cut}

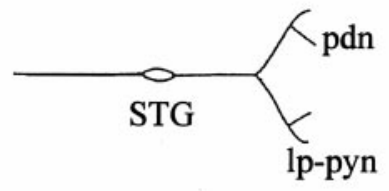

B- Day $1,+$ oxo lp-pyn

pdn

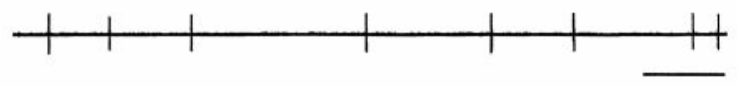

lp-pyn

pdn

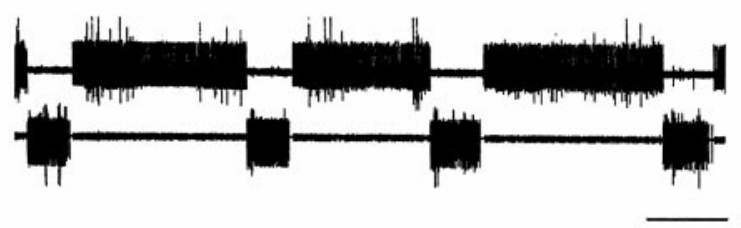

\section{C- Day 5, oxo rinsed}

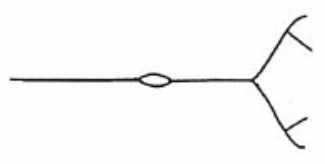

lp-pyn

pdn

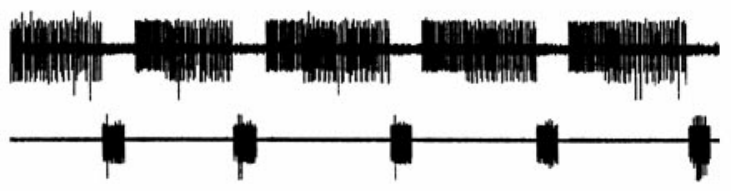

$1 \mathrm{~s}$

Figure 11. Recovery of pyloric rhythmicity in a continuously active decentralized STG. $A$, Absence of rhythm (right) in a freshly dissected STNS after stn transection (left). Recordings are from the lp-pyn and the pdn. B. Activation of the rhythm (right) by superfusion of $10^{-5} \mathrm{M}$ oxotremorine (oxo; left), which was replenished daily over the following $3 \mathrm{~d}$. $C$, Spontaneous pyloric rhythm on day 5 (right), $24 \mathrm{hr}$ after rinsing the muscarinic agonist from the preparation (left).

lasting phenomenon that extends beyond the temporal and experimental constraints of the Petri dish.

Initially, we were concerned that the stn terminals might be continuing to release modulatory substances after axotomy and that, in combination with the development of a type of postsynaptic "denervation supersensitivity" (Fambrough, 1979; but see Dunn and Marshall, 1985), might lead to the reactivation of the pyloric network. Moreover, the STG terminals themselves may be postsynaptic to the network neurons they influence (Nusbaum et al., 1992). Thus, at least in theory, local circuit interactions between nondegenerated, axotomized modulatory terminals and their pyloric targets could eventually promote and sustain network rhythmicity. However, our experiments with TTX-treated preparations indicated that if such processes were occurring, they did not rely on spike generation or spike-mediated synaptic activity. Furthermore, a stronger argument against any direct contribution of surviving input terminals is that re-establishment of pyloric rhythmicity after decentralization still occurred after their photoablation. Stn photoinactivation also unavoidably kills the $\mathrm{AB}$ interneuron, the sole nonmotor member of the pyloric network, the axon of which projects in the stn. Resumption of rhythmicity therefore does not require an intact network or the participation of the neuron considered to possess the strongest rhythmogenic properties in the network (Bal et al., 1988).

Given that the recovery process is a direct consequence of network decentralization, in principle either or both of two signaling mechanisms could be involved. One possibility is that in the absence of a permissive modulatory drive, pyloric neurons adjust their intrinsic properties as a direct consequence of their lack of rhythmic activity. Alternatively, functional recovery could arise from the loss of extrinsic inputs that otherwise continuously downregulate network excitability via a trans-synaptic process.

Evidence of activity-dependent regulation has derived from both dissociated cell culture (Turrigiano et al., 1994, 1995) and 
modeling experiments (LeMasson et al., 1993) on STG neurons. In this scheme, silent dissociated pyloric neurons are proposed to sense the lack of rhythmic drive from other pyloric neurons and to modify their membrane conductances so as to resume firing and eventually endogenous rhythmic bursting (Marder et al., 1996). An important prediction from this interpretation is that stimulating a cultured neuron that is already rhythmically active should reverse the process, inducing the cell to downregulate its conductances to produce a tonic mode of firing. Both experimental (Turrigiano et al., 1994) and theoretical (LeMasson et al., 1993 ) evidence from the responses of bursting pyloric neurons in culture to short-lasting $(\sim 1 \mathrm{hr})$ rhythmic stimulation indicate that this is indeed the case. However, the short time scale for this change suggests a different underlying process from the plasticity revealed in the present study.

Interestingly, solitary pyloric neurons in culture spontaneously develop an intrinsic burst-generating capability over a time scale (2-3 d) similar to that for the recovery of rhythmicity in our long-term decentralized organ cultures (see also Marder et al., 1996). However, there are a number of indications that signals in addition to the level of neuronal activity are involved. For example, using elevated extracellular potassium concentrations in the bathing saline to produce sustained depolarization of pyloric neurons did not diminish the capacity of the decentralized network to recover rhythmicity. This was somewhat surprising, because chronic depolarization in culture causes neuronal calcium currents to decrease gradually (Delorme and McGee, 1986; Franklin et al., 1992; Berdan et al., 1993), whereas an increase in $\mathrm{Ca}^{2+}$ channels seems to underlie the enhanced excitability necessary for the transition to burst firing in dissociated stomatogastric neurons (Turrigiano et al., 1995). In a similar vein, continuous exposure (over 3-4 d) to oxotremorine, a muscarinic agonist known to induce bursting in decentralized lobster pyloric neurons (Bal et al., 1988, 1994), failed to prevent or prolong network recovery. Neither of these observations are consistent with pyloric neuron activity-dependent type mechanisms underlying the recovery described here. Thus, the second possibility that the decentralized network is responding to the removal of extrinsic inputs that normally exert a sustained downregulatory influence on network excitability in addition to short-term neuromodulatory control arises. Whether such a long-term influence from modulatory inputs involves a trophic or growth factor remains to be seen, although such factors are known to play an important role in conventional cell-cell interactions, including the regulation of receptor/transmitter expression and levels of target cell excitability (Martinou and Merlie, 1991; Reist et al., 1992; Traynor et al., 1992). Moreover, precedent exists for negative regulation of adult neuronal properties by central nervous inputs (also revealed by ganglionic decentralization), such as the continual repression of neuropeptide biosynthesis in rat sympathetic neurons (Kessler and Black, 1982; Zigmond et al., 1992; HyattSachs et al., 1993). Indeed the intriguing possibility exists that pyloric network neurons themselves also produce novel neuroactive substances that are not normally expressed with intact central inputs.

How can this interpretation from our organ culture experiments be reconciled with earlier dissociated neuron data (Turrigiano et al., 1994, 1995; Marder et al., 1996)? Perhaps massively traumatized, rapidly outgrowing stomatogastric neurons in culture react differently than do neurons that remain relatively undisturbed within an entire decentralized ganglion. The molecular and cellular responses of central neurons differ according to direct and indirect injury (Weiser et al., 1994), and the time course and magnitude of a somatic response of a neuron to axotomy is closely related to lesion distance (Berdan at al., 1993). Explanted stomatogastric neurons generally have only a very short $(<200 \mu \mathrm{m})$ primary neurite (Graf and Cooke, 1990; Turrigiano and Marder, 1993), whereas in organ explants the nerve tracts containing pyloric motor axons are severed as far as 30-40 $\mathrm{mm}$ from the STG. An attractive possibility, therefore, is that the different in vitro preparations reveal separate extrinsic and intrinsic regulatory mechanisms that are not mutually exclusive but that normally operate conjointly in vivo; innervation-dependent, transsynaptic influences could serve to establish overall levels of (conditional) excitability in pyloric network neurons, whereas activitydependent processes could be responsible for their individual tuning and adjustment. Multiple strategies involving intrinsic and extrinsic processes are used in the short-term modulation of adult motor networks (Harris-Warrick et al., 1992; Katz, 1995); it is similarly not unreasonable to expect similar diversity in the origin and nature of their long-term control. Moreover, that modulatory inputs help maintain pyloric network rhythmogenesis in a dependent, rather than autoactive, state would render the network far more susceptible to short-lasting modulatory control.

\section{REFERENCES}

Angelides KJ (1986) Fluorescently labelled $\mathrm{Na}^{+}$channels are localized and immobilized to synapses of innervated muscle fibres. Nature 321:63-66.

Bal T, Nagy F, Moulins M (1988) The pyloric central pattern generator in crustacea: a set of conditional neuronal oscillators. J Comp Physiol [A] 163:715-727.

Bal T, Nagy F, Moulins M (1994) Muscarinic modulation of a patterngenerating network: control of neuronal properties. J Neurosci 14:3019-3035.

Beam KG, Caldwell JH, Campbell DT (1985) Na channels in skeletal muscle concentrated near the neuromuscular junction. Nature 313:588-590.

Berdan RC, Easaw JC, Wang R (1993) Alterations in membrane potential after axotomy at different distances from the soma of an identified neuron and the effect of depolarization on neurite outgrowth and calcium channel expression. J Neurophysiol 69:151-164.

Bittner GD (1988) Long-term survival of severed distal axonal stumps in vertebrates and invertebrates. Am Zool 28:1165-1179.

Black IB, Green SC (1973) Trans-synaptic regulation of adrenergic neuron development: inhibition by ganglionic blockade. Brain Res 63:291-302.

Cohen AH, Mackler SA, Selzer ME (1986) Behavioral recovery following spinal transection: functional regeneration in the lamprey CNS. Trends Neurosci 11:227-231.

Delorme EM, McGee R (1986) Regulation of voltage-dependent $\mathrm{Ca}^{2+}$ channels of neuronal cells by chronic changes in membrane potential. Brain Res 397:189-192.

Dunn PM, Marshall LM (1985) Lack of nicotinic supersensitivity in frog sympathetic neurones following denervation. J Physiol (Lond) 363:211-225.

Evinger MJ, Ernsberger P, Regunathan S, Joh TH, Reis DJ (1994) A single transmitter regulates gene expression through two separate mechanisms: cholinergic regulation of phenylethanolamine $n$-methyltransferase mRNA via nicotinic and muscarinic pathways. J Neurosci 14:2106-2116.

Fambrough DM (1979) Control of acetylcholine receptor in skeletal muscle. Physiol Rev 59:165-227.

Franklin JL, Fickbohm DJ, Willard AL (1992) Long-term regulation of neuronal calcium currents by prolonged changes of membrane potential. J Neurosci 12:1726-1735.

Goodman CS, Heitler WJ (1979) Electrical properties of insect neurones with spiking and non-spiking somata: normal, axotomized, colchicinetreated neurones. J Exp Biol 83:95-121.

Graf RA, Cooke IM (1990) Primary culture of crustacean stomatogastric ganglion neurones in a defined medium. J Exp Biol 149:521-525.

Harris-Warrick RM, Marder E, Selverston AI, Moulins M, eds (1992) 
Dynamic biological networks: the stomatogastric nervous system. Boston: MIT.

Hyatt-Sachs H, Schreiber RC, Bennet TA, Zigmond RE (1993) Phenotypic plasticity in adult sympathetic ganglia in vivo: effects of deafferentation and axotomy on the expression of vasoactive intestinal peptide. J Neurosci 13:1642-1653.

Jacob MH, Berg DK (1987) Effects of preganglionic denervation and postganglionic axotomy on acetylcholine receptors in the chick ciliary ganglion. J Cell Biol 1847-1854.

Katz PS (1995) Intrinsic and extrinsic neuromodulation of motor circuits. Curr Opin Neurobiol 5:799-808.

Katz PS, Harris-Warrick RM (1989) Serotonergic/cholinergic muscle receptor cells in the crab stomatogastric nervous system. II. Rapid nicotinic and prolonged modulatory effects on neurones in the stomatogastric ganglion. J Neurophysiol 62:571-581.

Kessler JA, Black IB (1982) Regulation of substance P in adult rat sympathetic ganglia. Brain Res 234:182-187.

Kuwada JY, Wine JJ (1981) Transient, axotomy-induced changes in the membrane properties of crayfish central neurones. J Physiol (Lond) 317:435-461.

Lehouelleur J, Cuadras J, Bruner J (1983) Tonic muscles fibres of crayfish after gangliectomy: increase in excitability and occurrence of sodium-dependent spikes. Neurosci Lett 37:227-231.

LeMasson G, Marder E, Abott LF (1993) Activity-dependent regulation of conductances in model neurons. Science 259:1915-1917.

Le Moine C, Normand E, Guitteny AF, Fouque A, Teoule R, Bloch B (1990) Dopamine receptor gene expression by enkephalin neurons in rat forebrain. Proc Natl Acad Sci USA 87:230-234.

Lupa MT, Krzemien DM, Schaller KL, Caldwell JH (1995) Expression and distribution of sodium channels in short- and long-term denervated rodent skeletal muscles. J Physiol (Lond) 483:109-118.

Marder E, Abbott LF, Turrigiano GG, Liu Z, Golowasch J (1996) Memory from the dynamics of intrinsic membrane currents. Proc Natl Acad Sci USA 93:13481-13486.

Martinou JC, Merlie JP (1991) Nerve-dependent modulation of acetylcholine receptor e-subunit gene expression. J Neurosci 11:1291-1299.

Meyer H, Prince D (1973) Convulsant actions of penicillin: effects on inhibitory mechanisms. Brain Res 53:477-482.

Miller JP, Selverston AI (1979) Rapid killing of single neurons by irradiation of intracellularly injected dye. Science 206:702-704.

Moulins M, Cournil I (1982) All-or-none control of the bursting properties of the pacemaker neurons of the lobster pyloric pattern generator. J Neurobiol 13:447-458.

Nagy F, Miller JP (1987) Pyloric pattern generation in Panulirus interruptus is terminated by blockade of activity through the stomatogastric nerve. In: The crustacean stomatogastric system (Selverston AI, Moulins M, eds), pp 205-242. Berlin: Springer.
Nusbaum MP, Weimann JM, Golowasch J, Marder E (1992) Presynaptic control of modulatory fibers by their neural network targets. J Neurosci 12:2706-2714.

Panchin YV, Arshavsky YI, Selverston AI, Cleland TA (1993) Lobster stomatogastric neurons in primary culture. I. Basic characteristics. J Neurophysiol 69:1976-1992.

Reist NE, Werle MJ, McMahan UJ (1992) Agrin released by motor neurons induces the aggregation of acetylcholine receptors at neuromuscular junctions. Neuron 8:865-868.

Rezer E, Moulins M (1983) Expression of the crustacean pyloric pattern generator in the intact animal. J Comp Physiol [A] 153:17-28.

Rezer E, Moulins M (1992) Humoral induction of pyloric rhythmic output in lobster stomatogastric ganglion: in vivo and in vitro studies. $\mathrm{J}$ Exp Biol 163:209-230.

Royer SM (1987) Chronic effects of de-afferentation on the stomatogastric ganglion of Panulirus. In: The crustacean stomatogastric system (Selverston AI, Moulins M, eds), pp 251-257. Berlin: Springer.

Selverston AI, Moulins M, eds (1987) The crustacean stomatogastric system. Berlin: Springer.

Thoby M, Simmers J (1997) Intrinsic plasticity of oscillatory neurons in the lobster pyloric network after longterm decentralization in vitro. Soc Neurosci Abstr 23:477.

Thoenen H, Edgar D (1982) The regulation of neuronal gene expression. Trends Neurosci 5:311-313.

Traynor P, Dryden WF, Smith PA (1992) Trophic regulation of action potential in bullfrog sympathetic neurons. Can J Physiol Pharmacol 70:826-834.

Turrigiano G, Abbott LF, Marder E (1994) Activity-dependent changes in the intrinsic properties of cultured neurons. Science 264:974-977.

Turrigiano G, LeMasson G, Marder E (1995) Selective regulation of current densities underlies spontaneous changes in the activity of cultured neurons. J Neurosci 15:3640-3652.

Turrigiano GG, Marder E (1993) Modulation of identified stomatogastric ganglion neurons in primary cell culture. J Neurophysiol 69:1993-2002.

Veskov R, Supljakov OV, Vesselkin NP, Rakic LJ (1989) Penicillininduced bursting in motoneurones of the frog spinal cord. Neuropharmacology 28:1119-1122.

Weiser M, Backer H, Joh TH (1994) Gene expression in central cholinergic neurons in response to axotomy and deafferentation. Synapse 16:81-92.

Zigmond RE, Hyatt-Sachs H, Baldwin C, Qu XM, Sun Y, McKeon TW, Schreiber RC, Vaidyanathan U (1992) Phenotypic plasticity in adult sympathetic neurons: changes in neuropeptide expression in organ culture. Proc Natl Acad Sci USA 89:1507-1511. 